Disponível em

http://www.anpad.org.br/rac

RAC, Rio de Janeiro, v. 17, n. 6, art. 1, pp. 642-660, Nov./Dez. 2013

$(\mathrm{co})$ EY-No

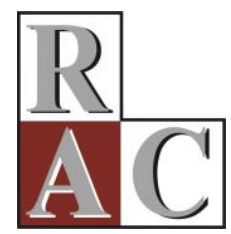

\title{
Reflexões Epistemológicas para a Pesquisa em Administração: Contribuições de Theodor W. Adorno
}

\author{
Epistemological Reflections on Business Administration Research: Contributions of \\ Theodor W. Adorno
}

\begin{abstract}
José Henrique de Faria E-mail: jhfaria@gmail.com Universidade Federal do Paraná - UFPR PPGADM/UFPR, Av. Prefeito Lothário Meissner, 632, $2^{\circ}$ andar, 80210-170, Curitiba, PR, Brasil.

Carolina Machado Saraiva de Albuquerque Maranhão E-mail: carola.maranhao@gmail.com Centro Universitário UNA Centro Universitário UNA, Av. João Pinheiro, 515, 30130-180, Belo Horizonte, MG, Brasil.

Francis Kanashiro Meneghetti E-mail: fkmeneghetti@gmail.com Universidade Tecnológica Federal do Paraná - UTFPR Av. Sete de Setembro, 3165, PPGTE, Sala 5, 80230-901, Curitiba, PR, Brasil.
\end{abstract}




\title{
Resumo
}

O pensamento de Adorno passou a ser considerado nas pesquisas também na área de administração, especialmente nos assim chamados estudos organizacionais (Batista-dos-Santos, Alloufa, \& Nepomuceno, 2010; Faria, 2004; Paes de Paula, 2008, 2012). O presente ensaio pretende contribuir para com as reflexões epistemológicas e suas implicações no uso da dialética como método de análise. A contribuição de Adorno para as pesquisas em administração se materializam em pelo menos 6 pontos: (a) combate à instituição dos sistemas totalitários de compreensão; (b) indicação de que, quando os pensamentos são elementos da práxis, estes passam a ter potencial concreto no mundo objetivo; (c) a primazia do objeto faz do sujeito um objeto qualitativamente distinto; (d) o objeto a ser estudado não é nada sem o sujeito que vai estudá-lo, pois, sem o sujeito, o momento do objeto não existe; (e) o sujeito pensa a realidade principalmente por concepções e por conceitos; (f) sendo a realidade estudada não plenamente cognoscível, aquilo que não se mostra somente pode ser conhecido por meio daquilo que se mostra, ou seja, o não conceito só pode ser conhecido por meio do conceito, pois a relação de mútua existência permite afirmar que existe uma totalidade em potência.

Palavras-chave: T. W. Adorno; teoria crítica; estudos organizacionais; dialética negativa.

\begin{abstract}
Adorno's philosophical legacy came to be considered in researches in the area of business administration, especially in organizational studies (Batista-dos-Santos, Alloufa, \& Nepomuceno, 2010; Faria, 2004; Paes de Paula, 2008, 2012). This paper is intended to contribute with epistemological reflections and their implications in the use of dialectic as a method of analysis. Adorno's contributions to research in organization studies materialize in at least 6 ways: (a) the fight against totalitarian philosophical systems; (b) when ideas are elements from Praxis, these have concrete potential in the objective world; (c) the primacy of an object over a subject makes an object qualitatively distinct; (d) an object studied is nothing without a subject who will study it, because without the subject the object does not exist; (e) a subject thinks about reality principally through ideas and concepts; (f) as any reality studied cannot be fully knowable, it can only be known through what it shows, i.e. a non-concept can only be known through a concept, because a relationship of mutual existence allows us to consider the existence of a potential totality.
\end{abstract}

Key words: T. W. Adorno; critical theory; organization studies; negative dialectics. 


\section{Introdução}

Theodor W. Adorno é, sem dúvida, um dos mais importantes intelectuais da Teoria Crítica pertencente à primeira geração da chamada Escola de Frankfurt (Claussen, 2008; Thomson, 2010; Wiggershauss, 1994; Wilson, 2007) ${ }^{(1)}$. A profundidade do seu pensamento requereu estudos detalhados da sua obra por parte daqueles que se propuseram a conhecer o teor específico de suas ideias. Jay (1984) trata da obra de Adorno como sendo de suma importância para a filosofia e para as diversas áreas do conhecimento e temáticas por ele tratadas. Entre as temáticas de reflexão desse filósofo, destacam-se a Indústria Cultural (Adorno \& Horkeheimer, 2002), o problema da pesquisa científica na sociologia alemã (Horkheimer \& Adorno, 1978), a moral danificada (Adorno, 1993a), a epistemologia (Adorno, 2001a), a metafísica (Adorno, 2001b, 2001c), o problema do irracionalismo na cultura (Adorno, 2002a), além da arte e a estética (Adorno, 2002b) e da música (Adorno \& Eisler, 1976).

No Brasil, além da sociologia, da política, do direito, da educação e da filosofia, parte de seus trabalhos passou a ser considerada nas pesquisas também na área de administração, especialmente nos assim chamados estudos organizacionais. Batista-dos-Santos, Alloufa e Nepomuceno (2010) mostram, em um estudo sobre a produção acadêmica, a importância crescente de Adorno como referência nos estudos organizacionais. Publicações como as de Faria (2004), Paes de Paula (2008, 2012), Maranhão e Vilela (2010), Maranhão (2010) e Faria e Meneghetti (2011), por exemplo, ajudam a corroborar a importância do pensamento de Adorno na área. Mesmo com sua importância crescente e com suas contribuições inovadoras, tais estudos ainda não foram suficientemente explorados na área de administração, podendo e devendo ser aprofundados, sobretudo pela contribuição teórica de Adorno ao conhecimento de fenômenos atuais. Levando em consideração os estudos desenvolvidos nas ciências sociais, na educação e no direito, bem como os impactos teóricos e epistemológicos que as discussões e reflexões sobre o pensamento adorniano podem trazer, o mesmo, na área de administração, ainda pode ser considerado modesto.

Não se pretende aqui dar conta de preencher essa lacuna, mas de avançar um pouco mais nessa linha de investigação. Assim, com o intuito de aprofundar as reflexões sobre o pensamento de Adorno consideradas fundamentais, este estudo se propõe a enfrentar cinco questões: (a) O que é a Dialética Negativa? (b) Quais as características do materialismo não ortodoxo em Adorno? (c) Como se dá a relação sujeito $\leftrightarrow$ objeto e o que é o primado do objeto? (d) Como se caracterizam as constelações e o que é conceito? (e) Quais as contribuições epistemológicas possíveis para a pesquisa em administração e estudos organizacionais a partir das reflexões desenvolvidas neste artigo?

O artigo contribui para reflexões epistemológicas e suas implicações no uso da dialética como método de análise. É preciso, desde logo, indicar que a dialética, enquanto método do materialismo histórico, difere da dialética da fenomenologia hegeliana e ambas diferem da dialética negativa adorniana. Conhecer a Dialética Negativa possibilita, portanto, reavaliar os caminhos que as pesquisas que possuem uma orientação da dialética estão percorrendo, em especial as que se vinculam à Teoria Crítica, compreendendo que essa teoria e o projeto marxiano não se confundem. Outra importante discussão que é feita neste artigo é sobre a relação sujeito $\leftrightarrow$ objeto, questão central na filosofia do conhecimento desde Platão e Aristóteles, que adquire em Kant (2008a, 2008b) uma grande importância. O artigo provoca reflexões ainda em relação ao que é conceito e como ele está relacionado com a noção de constelação. Por fim, analisa certas práticas na pesquisa em administração.

\section{A Dialética Negativa}

A Dialética Negativa desperta interesses de vários estudiosos, como Buck-Morss (1977), Chiarello (2007), Duarte (2007), Jameson (1997), Maar (2006), Musse (2003, 2007), O’Connor 
(2004), Nobre (1998) e Rose (1978). A obra considerada a mais complexa e a síntese do percurso intelectual de Adorno (2009) desperta questionamentos e reflexões profundas sobre o que é abordado a respeito da dialética.

A expressão 'dialética negativa' subverte a tradição. Já em Platão, 'dialética' procura fazer com que algo positivo se estabeleça por meio do pensamento da negação; mais tarde, a figura de uma negação da negação denominou exatamente isso. O presente livro gostaria de libertar a dialética de tal natureza afirmativa, sem perder nada em determinação. (Adorno, 2009, p. 7).

A tradição a que Adorno se refere está relacionada à forma como a dialética se desenvolveu desde Platão até os filósofos da modernidade, como Hegel e Marx, por exemplo. Além disso, Adorno (2009) alerta para o estranhamento de muitos com o título adotado: Dialética Negativa. Ao defender um tipo de dialética sem síntese, "desconserta até alguns de seus simpatizantes, enquanto provoca em outros críticos francamente hostis a ela uma reação tão virulenta quanto equivocada, já que a classificam como irracionalista" (Pucci, Goergen, \& Franco, 2007, p. 11).

Adorno pretende com o texto contestar a necessidade da dialética de obter sínteses de natureza afirmativa, pois esta prática estava associada à tradição idealista. Com essa crítica, Adorno quer estabelecer um novo estatuto materialista para a dialética, em que a síntese não é em si mesma a afirmação de algo como consequência do princípio da contradição. Com isso, Adorno (2009) realiza o que foi considerado um novo giro na filosofia, ao desarticular a lógica identificatória da dialética, derivada de uma visão idealista da filosofia. Ao desenvolver o conceito de Dialética Negativa, Adorno propõe uma dialética sem síntese e sem a tentativa de classificar a totalidade dos fenômenos sociais pelas categorias de análise. Esse giro na filosofia parte de um materialismo não dogmático, caracterizando a ideia como objeto e desvelando o sentido dos conceitos, através do seu próprio processo de constituição. A concepção de uma dialética sem síntese não é uma criação de Adorno. Marx (2011) mesmo vai argumentar que não pode haver uma interpretação definitiva porque a realidade está em contínua mudança, de forma que a síntese de um fenômeno não é senão a tese de outro.

Porém, Adorno (2009) dá um novo sentido para a contradição, no qual a totalidade dela é uma não verdade da identificação total. Isso não quer dizer que a contradição seja uma ilusão, mas um elemento que se identifica pela não identidade. Contradição para Adorno (2009) não é o contrário de algo ou mera oposição, é algo diferente do ente que o pensamento elabora como não identidade. Mas o que Adorno pretendia com a compreensão da não identidade como o momento de realização da dialética? Uma de suas pretensões era combater a instituição dos sistemas totalitários de compreensão, presentes na tradição da dialética desde Platão até Hegel (Adorno, 1993a). Adorno ainda quer dar um novo entendimento sobre a dialética transcendental em Kant (Adorno, 2001a) e contestar o pensamento de Heiddeger em relação à noção de ser e ente, reflexões presentes na primeira parte do livro de Adorno (2009) da Dialética Negativa.

Essa empreitada da análise do pensamento heideggeriano tem motivações concretas: lutar contra o sistema de compreensão totalitário na Alemanha, que influenciou fortemente a filosofia que serviria de fundamento filosófico de parte do nazismo (Lukács, 1959). A noção de Saber Absoluto da dialética de Hegel (2008), por exemplo, constituir-se-ia para o sistema de pensamento totalitário apropriado pelos intelectuais do nazismo como a justificativa de que os meios para se chegar ao Saber Absoluto são legítimos, e que somente uma raça superior de intelectuais teria condições de conduzir a sociedade até ele.

Para Adorno (1991, 2009), os homens são eles mesmos responsáveis por seus próprios destinos. Com a crítica feita à instituição de um Saber Absoluto como a chegada a uma síntese de verdade absoluta e de identidade total, Adorno quer responsabilizar os homens pelos seus próprios pensamentos, em que o momento da identidade só ocorre no sujeito como um para-si e não como um em-si mesmo. Não se trata de uma filosofia especulativa do sujeito, mesmo porque, para a Dialética Negativa, o primado é do objeto potencializado, nem de uma metafísica subjetivista de natureza bergsoniana, mas de responsabilizar os homens pelos acontecimentos concretos a que são submetidos. 
Assim, um de seus objetivos principais é a consciência, por parte da filosofia, da necessidade de que "o sofrimento radical experimentado pelo homem contemporâneo, atônito diante da opressão e massacres de efeito multiplicado pela tecnologia, manifeste-se a partir do núcleo mesmo do discurso filosófico, não como algo externo, adicionado a partir de fora" (Duarte, 2007, p. 19). Dito de outro modo, não há um lugar, uma ideia ou um fenômeno absoluto que se impõe sobre a ação humana como algo que não lhe pertence, um assim mesmo transcendental, uma inevitabilidade da natureza.

No âmbito da crítica que algumas correntes marxistas fazem à proposta de Adorno, é preciso destacar, em primeiro lugar, que a crítica de Adorno ao Saber Absoluto foi desencadeada por Feuerbach e reafirmada por Marx (2010, p. 12).

Ao conceber a negação da negação, sob o aspecto da relação positiva a ela inerente, como a única verdadeiramente positiva, e sob o aspecto da relação negativa a ela inerente, como o único ato verdadeiro, e que se confirma a si próprio, de todo o ser, Hegel descobriu simplesmente uma expressão abstrata, lógica e especulativa do processo histórico, que ainda não é a verdadeira história do homem como um dado sujeito, mas apenas a história do ato de criação, da gênese do homem.

Em segundo lugar, é necessário separar o marxismo mecanicista e o estruturalista do materialismo histórico. A versão mecanicista aposta em uma inevitabilidade lógica entre a tese, a antítese e a síntese, independentemente do sujeito. Nessa versão, um modo de produção superior não pode ser impedido no curso da História, pois o mesmo pertence a ela como algo contido nela mesma. De certa forma, a concepção estruturalista caminha na mesma direção, pois propõe uma dialética sem sujeito, um mundo de determinações e de reproduções. Para a primeira versão, a História cumpre um papel determinista na qual as formas de organização da sociedade são derivadas de argumentos sociais. Para a segunda versão, trata-se de um materialismo racionalista, no qual a sociedade é concebida como um todo estruturado, de modo que a intervenção da atividade humana resta reduzida a períodos de transição. Para o materialismo histórico, a discussão sobre a síntese não se trata de uma imposição, nem da realidade e nem do pensamento, mas do entendimento de que a mesma pode estar em processo em determinadas fases do desenvolvimento histórico, e que sua consecução é um momento de transformação de um processo e ao mesmo tempo de criação de outro. As urgências de Marx e de Adorno não são as mesmas. Para Marx, a síntese é a superação da contradição histórica e a totalidade corresponde a uma análise não fragmentada. Marx (2013) critica o lado místico da dialética hegeliana com a finalidade de dar conta das formas historicamente desenvolvidas em movimento. A dialética "não se deixa intimidar por nada e é, por essência, crítica e revolucionária" (Marx, 2013, p. 91). Para Adorno, qualquer conteúdo pode levar a um dogmatismo, expulsando a negatividade da dialética, de maneira que a crítica dialética é um permanente estado de autocrítica, pois a dialética negativa não descansa sobre si mesma como se fosse, ela mesma, uma totalidade.

A urgência de Adorno, impulsionada pela preocupação de que Auschwitz não se repita (Adorno, 1973), é permanente, por isso sua ênfase com a educação, primeiro local para a instrução do pensamento. $\mathrm{O}$ estatuto do pensamento (que é concreto para Adorno) é um a priori para a existência da humanidade. Em Dialética do Esclarecimento, Adorno e Horkheimer (2002) manifestam profunda preocupação como a Indústria Cultural, fazendo uma crítica à sua instituição como um sistema ideológico e totalitário. Ideológico porque possui elementos concretos capazes de disseminar a ideologia dominante para todos os âmbitos da sociedade (família, lazer, etc.). Totalitário porque é capaz de criar um sistema de pensamento altamente alienante, em que os homens são presos em uma rede de símbolos e sistemas de compreensões que reforçam e ampliam a alienação em relação à dominação econômica do capitalismo.

Para Adorno, o pensamento é concreto, por isso tem força para emancipar ou alienar. Para ele, "o pensar é pensar em algo" (Adorno, 2009, p. 37). Pensar requer um ente. Não existe "nenhum ser sem ente" (Adorno, 2009, p. 119). O ser pensa por meio de conceitos, ente elementar para que o próprio pensamento exista. O conceito é substrato mesmo do ser. Este, por sua vez, é a "abstração mais extrema do caráter coisificado não idêntico ao pensamento" (Adorno, 2009, p. 119). Essa abstração mínima não pode ser abolida por nenhum outro pensamento, pois sem ela a lógica não 
poderia ser pensada. Quando os pensamentos são elementos da práxis, esses passam a ter potencial concreto no mundo objetivo. Com isso, é possível agir na condição de transformar o mundo (Vásquez, 1977), organizá-lo, modificá-lo, ou simplesmente se alienar a ele, aceitar que outros o façam. Ser passivo não quer dizer que não se pensa sobre algo, mas sim que se aceite esse algo. Mesmo não pensar é pensar sem perceber que se aceita aquilo que já está dado. Por isso, um fenômeno como Auschwitz é responsabilidade de todos. A omissão não é mera ausência de ação que torna as pessoas não responsáveis pelo fato, mas sim a renúncia para que o pensamento dominante possa agir livremente.

Pensar em algo "é, já em si, antes de todo e qualquer conteúdo particular, negar, é resistir ao que lhe é imposto" (Adorno, 2009, p. 25). Um sistema de pensamento na posse de pessoas pouco conscientes sobre as consequências do capitalismo funciona como uma fábrica de racionalidades, capaz de dar respostas lógicas e justificadas para as atitudes mais bárbaras do mundo. Para Adorno, a barbárie como fenômeno regressivo no mundo moderno tornou-se ainda pior do que outros períodos históricos. A regressão à violência do homem contra o homem é acompanhada de sistemas racionalizados que retiram a responsabilidade daqueles que estão um pouco mais distantes do fato. Tornam expectadores os homens que não participam diretamente dos atos de barbárie. A lógica do mundo moderno é a de que quem não participa não é culpado, ou seja, de que a omissão é a legitimação justificadora da não responsabilidade, quando esta é, de fato, apenas mais uma forma de transformar o terror em entretenimento.

É assim que, na Dialética Negativa, o pensamento passa a ser guiado pelo princípio da não identidade. Esta é a forma de resistência à tendência de sistematizações identificatórias a partir da instituição de identidades afirmativas que ocorre na dialética idealista, baseada na síntese idealista. A Dialética Negativa procura desmitificar o conceito como algo definitivo. Procura questionar o falso conceito revelando "sua materialidade, [onde] é revelado, então, o primado do objeto ${ }^{(2)}$, esse é o momento em que a dialética negativa se instala" (Adorno, 2009, p. 197). A materialidade do conceito subsiste exatamente onde o mesmo foi produzido, e para que finalidade e alcance.

Adorno, tal como Marx, não nega a importância da dialética hegeliana. Quer apenas livrá-la da tendência idealista da absolutização do saber como algo que tem um fim, o Saber Absoluto. O legado da Dialética Negativa é evitar que qualquer forma de sistema de pensamento torne-se absoluto e se imponha como verdade única e definitiva. Para que isso não ocorra, é necessário questionar o pensamento pelo próprio pensamento. Com o princípio da não identidade, Adorno procura evitar que o pensamento caia na armadilha de que ele possa ser a própria realidade em si e não um momento do para si na compreensão do objeto.

Essa proposição adorniana, do ponto de vista dos estudos organizacionais, permite uma crítica à tendência da teoria da administração em sistematizar conceitos como racionalidades definitivas, tal como, por exemplo, na clássica definição da Administração enquanto produto cartesiano de uma relação funcional, em que Administração $(f)=\{$ Planejar, Organizar, Dirigir, Controlar $\}$. As teorias definitivas, assim, ocupariam um lugar no saber administrativo não como reflexo do movimento, mas como algo dado, cumprindo a finalidade para a qual as mesmas foram produzidas e seu alcance universal, ou seja, a teoria da administração, seria a própria realidade e não um momento para compreendê-la.

Para conhecer os pressupostos ontológicos da Dialética Negativa, é necessário compreender seu elemento fundamental, que é o que Adorno entende por materialismo.

\section{O Materialismo Não Ortodoxo em Adorno}

A compreensão do materialismo não ortodoxo de Adorno ficou expressa no que se convencionou chamar de projeto metodológico, presente na Dialética Negativa. É na relação sujeito 
$\leftrightarrow$ objeto que o projeto metodológico pode ser conhecido. Mas, antes disso, é fundamental compreender o que é o materialismo não ortodoxo em Adorno.

Segundo Adorno (2009, p. 168), "Marx tinha acentuado a sua formulação do materialismo histórico contra o materialismo vulgar". Apesar disso, o materialismo vulgar continuou sua empreitada nas reflexões filosóficas e sociológicas. Em alguns momentos, o materialismo vulgar se manifestou em certos marxismos mecanicistas, tais como o stalinista, e em certas formas de estruturalismos, como o de Althusser (1967), Althusser e Badiou (1979).

Para Adorno (2009), o materialismo não é uma ideologia, mas um princípio ontológico, um fundamento basilar de qualquer ente. O ente é material, e mesmo o sujeito que pensa, e o seu próprio pensamento, é material. O sentido material da tese de Adorno é sua vinculação com a compreensão: (a) da expressão dos objetos (ideias e sujeitos também são objetos), ou seja, possibilidade concreta, factual; (b) das constelações de ideias que os geram (a revelação de seus vínculos históricos e condições concretas de realização); (c) da capacidade de experiência ${ }^{(3)}$ do homem no mundo, ou seja, a faculdade do sujeito de ser sujeito, de experimentar o mundo em suas condições concretas de realização e de vislumbrar a existência para além do aí está. Essa possibilidade de experiência formativa (conceito tomado de Kant) é elemento do esquematismo kantiano apontado na obra de Adorno por diversos autores (Duarte, 2007; Rüdiguer, 2004). Esse esquematismo refere-se à capacidade dos sujeitos de interpretarem o mundo, significando-o, julgando-o e prospectando ações humanas mais esclarecedoras na vida em sociedade. Todos esses elementos (expressão, constelação de ideias, experiência formativa e esquematismo kantiano) constituem o conceito de imagens dialéticas e reforçam sua tese de primazia do objeto. Assim, a objetividade material na obra de Adorno não deve ser tomada em sentido imediato. O materialismo apresenta-se mediatizado "na figura de uma efetividade caracterizada no presente como utópica" (Maar, 2006, p. 139). O concreto é fruto das possibilidades realizadas e das não efetivadas, no que é considerado a aparência do mundo concreto, conforme a tese idealista. Essa projeção para o futuro, própria do significado de materialismo não dogmático de Adorno, revela um mundo de experiências humanas construídas para além das condições materiais. Essas projeções, no entanto, estão enraizadas na vida concreta material, associadas às efetividades das condições culturais do homem, e essas condições são sua realização e negação, sua identificação e contradição, sua emancipação e alienação. Essa característica dialética é o cerne da crítica negativa de Adorno.

Na concepção de Adorno (2009), seria improvável que o materialismo tivesse uma compreensão adequada do sujeito, pois a objetividade seria reduzida aos termos concretos de sua configuração. A subjetividade dialética seria, destarte, relegada ao campo da utopia. Para Adorno (2009), o conceito de dialética tem tido um significado particular, inclusive em algumas das assim chamadas teorias marxistas, qual seja, uma maneira eminentemente idealista de compreensão do mundo empírico, criando uma lógica identificatória entre as realidades particulares e o "movimento específico na história" (Horkheimer como citado em Maar, 2006, p. 135). Para Adorno, a perspectiva materialista não dogmática define: "o que está em causa não é menos sujeito, mas mais sujeito" (Maar, 2006, p. 140). O objeto, dessa maneira, é aquilo que é determinado pelo Espírito, o que é pensado, o que é trazido à consciência. $\mathrm{O}$ objeto é o que foi subordinado ao pensamento. Ao mesmo tempo, ele é independente do ser. Ele se apresenta à revelia do conceito. Por isso, o materialismo se apresenta como princípio ontológico, mesmo que não possa ser identificado de imediato.

O processo de objetivação acaba afastando esse entendimento de que o ente é material, pois, no processo de objetivação, o pensamento potencializa-se nas racionalidades que se apresentam. $\mathrm{O}$ pensamento ganha força e parece desligar-se do seu ente. Quando um sistema de pensamentos se forma, o afastamento com o princípio ontológico cria a ilusão de que o pensamento é mais importante que o objeto, ou seja, no objeto pensado o pensar é considerado o elemento essencial. Mas o pensar é sempre pensar em algo e para tal é necessário o ente.

Partindo dessa compreensão, percebe-se que a primazia do objeto nada tem de objetivismo, mas sim de objetividade. Ela não anula a razão. Ao contrário, vem na contramão da perspectiva da prioridade do "ser sobre a consciência" (Maar, 2006, p. 139), que tem servido para o estabelecimento 
da intentio recta em seu conteúdo de verdade. Como Adorno faz isso? Ele conceitua consciência como consciência de algo. Para o filósofo, ela não se realiza na desvinculação com o mundo concreto. Ademais, o ser é também objeto - processo de contradições na realização do homem nas condições materiais de vida.

É preciso evitar a elaboração, não incomum, de uma interpretação adorniana que parte do princípio de que uma ideia aplicada na constituição de um fato nasceria da própria ideia ou de um encadeamento de ideias. Tal interpretação nasce de uma crítica a determinado marxismo fenomenológico e, para respondê-la, deve-se recorrer ao próprio Marx (2010, p. 33):

O pensador abstrato descobre, ao intuir a natureza, que as entidades que ele julgava estar criando do nada, da abstração pura, criando na dialética divina como produtos puros do pensamento interminavelmente em vaivém dentro de si mesmo e sem nunca levar em conta a realidade exterior, são simplesmente abstrações de características naturais. A natureza inteira, por conseguinte, reitera para ele as abstrações lógicas, mas de uma forma sensível, exteriorizada. Ele analisa a natureza e essas abstrações, uma vez mais. Sua intuição da natureza é simplesmente, pois, o ato de confirmação de sua abstração da intuição da natureza; sua representação consciente do processo de geração de sua abstração.

É necessário reafirmar a crítica: a ideia que se transforma em realidade nasce sem contágio com a realidade a ser gerada, ou seja, a realidade é um produto partenogenético, em que a ideia produz a si mesma sem a fecundação do real. Como observa Marx (2010), a ideia teria que se revogar a si mesma para não passar novamente pelo processo de abstração e ser uma totalidade de abstrações. Isso seria uma abstração capaz de se entender a si mesma. Contudo, essa abstração capaz de se entender a si mesma não é nada além de uma abstração.

O materialismo não ortodoxo de Adorno funda-se em uma ontologia que procura se desvencilhar do domínio de certa metafísica que dominou a filosofia alemã. Mesmo as filosofias de base materialista são impregnadas de elementos idealistas quando atribuem à síntese dialética uma verdade em si mesma. Esta crítica não apresenta nenhuma novidade com relação à que Marx fez a Hegel e aos materialistas hegelianos (Marx, 2010). Para Adorno, a síntese é um para si, que se institui para o sujeito (individual e coletivo) que pensa. Pelo primado do objeto, em que o ente se constitui como elemento material, o sujeito que pensa chega a identidades provisórias, pois, conforme Adorno (1993a) mesmo afirma, o sujeito não é capaz de conhecer a realidade por força do pensamento. Isso não implica atribuir à filosofia adorniana o princípio do irracionalismo, pois, para ele, a racionalidade deve ser construída objetivamente e não se instituir como um sistema de compreensão da realidade baseado no idealismo, em entes que têm por suporte uma metafísica dogmática. Faz-se agora necessário entender a relação sujeito $\leftrightarrow$ objeto, fundamental para compreender como Adorno define o primado do objeto, pressuposto central na filosofia de Adorno.

\section{A Relação Sujeito $\leftrightarrow$ Objeto e o Primado do Objeto}

Sujeito e objeto existem concretamente. Mesmo assim, a definição conceitual de ambos é uma difícil tarefa. Ambos só podem ser entendidos como conceitos que se definem na relação mútua a partir do primado do objeto. Levando em consideração que o sujeito também é objeto, a princípio seria fácil achar uma saída lógica para construir uma compreensão de ambos, afinal, apenas a definição de objeto já seria suficiente. Entretanto, ambos são mediados por elementos que na aparência interferem de formas diferentes em cada um. O sujeito que pensa para estabelecer uma compreensão para ambos, fá-lo de forma influenciada por toda história vivida por ele, pelas racionalidades existentes, pelo sistema de compreensão dominante, pela limitação da própria consciência. Essas influências podem impor a primazia do sujeito devido à onipotência da consciência. 
Conforme afirma Adorno (1995, p. 182), os conceitos de sujeito e objeto têm prioridade em comparação a qualquer outro conceito. Entretanto, Adorno destaca a dificuldade da definição de sujeito e objeto. Isso não implica em renunciar à tal tentativa e cair em relativismo, irracionalismo ou convencionalismo como recurso para compreendê-lo. Essas soluções para estabelecer um entendimento para o sujeito e o objeto são recursos comuns das filosofias pós-modernas. Em Adorno, a compreensão do que é o sujeito e o objeto se fundamenta em uma objetividade materialista.

O elemento da contradição presente na separação entre sujeito e objeto está associado à possibilidade de uma inteligibilidade sobre ambos e as suas relações possíveis. É fato que se pode prescindir de pensá-los como entes separados. Entretanto, é importante tomar cuidado com as possíveis falsidades que a própria separação entre sujeito e objeto manifesta devido à sua separação aparente. Ambos encontram-se mediados reciprocamente. "A separação torna-se ideologia, exatamente sua forma habitual, assim que é fixada sem mediação. Uma vez radicalmente separado do objeto, o sujeito já reduz este a si; o sujeito devora o objeto ao esquecer o quanto ele mesmo é objeto" (Adorno, 1995, p. 183).

No movimento do sujeito compreender o objeto pela forma do pensamento, ele mesmo se percebe como algo diferente do objeto. Entretanto, "o sujeito é o sujeito do conhecimento, que, por sua vez, 'domina' o objeto, subordinando-o ao geral; mas também é um objeto entre os objetos, isto é, sujeito particular entre outros" (Maar, 2006, p. 140).

Eles estão relacionados um ao outro, com determinações objetivas. Todavia, a autonomização do sujeito o faz acreditar que ele é sempre um "algo a mais" que o próprio objeto. Mesmo a prática de pensar faz com que o sujeito acredite que existe algo potencialmente superior ao seu pensamento, como algo que está no plano de uma metafísica. O sujeito tende a acreditar que um vir-a-ser pode se realizar em uma síntese final, como um Saber Absoluto. Quando o pensamento autonomiza-se por entender ser um elemento totalmente independente da matéria, o mesmo acredita ser parte de uma objetividade transcendental.

Essa separação da herança kantiana, a separação entre sujeito transcendental e mundo material, cria uma ilusão de uma separação entre o mundo físico e a existência de uma metafísica, em que esta tem primazia sobre o outro. Quando isso acontece, o sujeito concreto, ou seja, aquele que é também objeto, passa a ser entendido como coisa frente à existência de um sujeito transcendental, separado do mesmo sujeito concreto.

Dessa forma, estabelece-se uma dialética sujeito $\leftrightarrow$ objeto em que o pensamento é sempre algo a mais que o próprio mundo concreto. Com isso, o sujeito concreto é reduzido a um segundo plano. Ele passa a ser meio e não fim em si mesmo. Cada sujeito transcendental compreende que é um fim em si mesmo e faz do outro, visto como objeto, um meio e não o próprio fim em si mesmo. Essa separação entre sujeito transcendental e sujeito concreto é contestada por Adorno. Sujeito é também objeto para ele, identificado como diferente na relação sujeito $\leftrightarrow$ objeto. O sentido atribuído por Adorno (2009) ao sujeito enquanto objeto torna concreta a experiência formativa, por exemplo, pois exige deste sujeito concreto uma interação permanente com o mundo das coisas e o mundo das ideias. O sujeito se afirma também como objeto pelo ato de interação com os objetos, inclusive com aqueles que são referências na constituição do pensamento.

Com isso, Adorno (2009) defende a tese do primado do objeto. Sua tese é considerada controversa. Muitos de seus leitores, dentre os quais se destaca Habermas (1990), rotularam o filósofo de idealista, caracterizando seus pensamentos como o gérmen do pós-modernismo. Contudo, quando Adorno (2009) ampara seus fundamentos no materialismo não ortodoxo e estabelece a existência de um primado do objeto, aceitando que mesmo o sujeito se apresenta como um objeto, ele institui uma recusa à tradição idealista.

Para Adorno (1995, p. 197), "a diferença entre sujeito e objeto perpassa tanto o sujeito quanto o objeto. Ela não deve ser absolutizada nem apagada do pensamento". No sujeito propriamente tudo é imputável ao objeto; o que nele não é objeto faz estalar semanticamente o É. Com isso, segundo Maar 
(2006), a tese do primado do objeto em Adorno é composta de dois significados: (a) determinação recíproca entre sujeito e objeto; (b) estatuto real de sujeito e objeto na relação entre pensamento e mundo.

O fato é que "o objeto só pode ser pensado por meio do sujeito" (Adorno, 2009, p. 158), mas o sujeito sempre se mantém como outro diante do objeto. O fato de o sujeito ser ele próprio objeto que se propõe a conhecer objetos faz com que seja percebido como algo anterior ao próprio objeto que pensa. "Não é possível abstrair o objeto do sujeito, nem mesmo enquanto ideia; mas é possível esvaziar o sujeito do objeto" (Adorno, 2009, p. 158).

A primazia do objeto faz do sujeito um objeto qualitativamente distinto, que requer radicalidade para conhecer o objeto. O objeto só pode ser conhecido pela consciência, e isso o torna algo qualitativamente distinto. As alterações qualitativas do objeto só são possíveis devido ao sujeito ser possuidor de opiniões da consciência coisificada (Adorno, 1995, p. 190). Por isso, um objeto não pode ser conhecido na sua totalidade, pois a consciência de algo é consciência reificada, um momento específico do objeto percebido por sujeitos que faz do pensamento um momento de identidade que se realiza na realidade pela não identidade.

Por outro lado, o objeto não é nada sem o sujeito cognoscente. Sem o sujeito, o momento do objeto não existe. O sujeito concreto - objeto, portanto, fruto das condições materiais existentes - é desafiado a criar seus esquemas e sua capacidade de julgar, sob o risco de ser levado a interpretar o mundo tal como lhe é apresentado pelos esquemas prontos. Cabe ao sujeito refletir permanentemente sobre sua ação de conhecer o objeto. É o sujeito concreto que deve questionar as verdades dadas como prontas por sistemas de interpretações definitivas.

Assim, para Adorno (2009, p. 151), "o sujeito nunca é em verdade totalmente sujeito, o objeto nunca é totalmente objeto; não obstante, os dois não são arrancados de um terceiro que os transcenderia". Observa-se que Adorno critica uma transcendência fora da relação sujeito $\leftrightarrow$ objeto. Essa crítica pode ser observada na tese de Adorno (2001a) sobre Kant. Com isso, o estatuto do conceito kantiano é questionado, pois a materialidade das ideias não pode ser suprimida. $\mathrm{O}$ espírito kantiano é material. Os conceitos são materiais. A materialidade do mundo objetivo, porém, é fruto da consciência e o "pensar em relação à realidade ... é pensar sobre as formas e estruturas do pensamento do sujeito e aquilo que este não é" (Adorno como citado em Maar, 2006, p. 134). A capacidade do sujeito de lidar com a característica dialética do real é a própria experiência. O que Kant esconde é uma metafísica baseada na existência determinada por uma transcendentalidade. Para Adorno (2009), se fosse possível uma transcendência, ela se realizaria na relação sujeito $\leftrightarrow$ objeto, em que a transcendência não seria algo além dos enganos proporcionados pela consciência absolutizada na tendência em estabelecer identidades que são elevadas a verdades pela onipotência do sujeito. Na dialética idealista, mesmo no idealismo disfarçado de Kant, o primado é do sujeito absoluto.

Para Adorno, a diferença entre sujeito e objeto não pode ser simplesmente negada. Eles não são unidades últimas e não são uma unidade derradeira mediada por elementos transcendentais. Eles se constituem pela relação mútua e toda forma de conhecimento possível só ocorre na mediação da relação sujeito $\leftrightarrow$ objeto. O cognoscível possível é aquele que resulta das contradições do pensamento fundamentado no princípio da não identidade. Assim, "o primado do objeto significa o progresso da diferenciação qualitativa daquilo que é mediado em si, um momento da dialética que não se acha para além dela, mas se articula nela" (Adorno, 2009, p. 158). Isso implica que o "o primado do objeto enquanto algo que é mediado por si mesmo não rompe a dialética do sujeito e do objeto" (Adorno, 2009, p. 160). A Dialética Negativa de Adorno é um vir a ser permanente, em que o fim possível não se apresenta como Saber Absoluto. "Por meio da passagem para o primado do objeto, a dialética tornase materialista" (Adorno, 2009, p. 165).

O tema do primado do objeto em Adorno ainda é pouco estudado e compreendido, apesar de ser central na concepção de mundo do filósofo. Adepto ao que Maar (2006) considerou como um materialismo não dogmático, Adorno posiciona-se criticamente ao idealismo, que, em sua concepção, ao manter-se como perspectiva da dialética, embrutece-a. Adorno inaugura uma vertente filosófica 
baseada na crítica radical ao idealismo. A primazia do objeto sempre foi para Adorno uma questão importante. Desde o início de sua carreira na universidade, já se pode encontrar suas críticas à visão idealista de mundo, como o demonstram seus escritos sobre música e sobre a crítica ao idealismo alemão. Porém, com o retorno de Adorno à Alemanha e à Universidade de Frankfurt após a Segunda Guerra, essas questões ficam mais latentes para o cientista social ${ }^{(4)}$. As contribuições que se pode perceber são: (a) o fato de o autor ocupar uma cadeira na escola de Sociologia da Universidade de Frankfurt, não mais professor de filosofia; (b) suas experiências largas em pesquisa empírica, principalmente no período em que ficou nos EUA; (c) o amadurecimento de sua concepção de crítica social. Não se pode deixar de observar a motivação pessoal que seu retorno ao país natal proporcionou em sua busca por compreender, de maneira empírica, como Auschwitz foi possível ${ }^{(5)}$.

Elegendo a pesquisa social como prioritária, Adorno (2009) foi coerente com sua defesa sobre o primado do objeto, pois ele, sendo um dos sujeitos cognoscentes, só poderia fazê-lo por meio da defesa da primazia do objeto. Esses fatos marcaram sua produção teórica, fazendo com que sua tese sobre a primazia do objeto ficasse cada vez mais evidente. O debate com Popper, em 1961, ainda que tenha sido aquém das expectativas dos presentes, pode ser considerado um marco no estímulo às publicações de Popper e de Adorno posteriores ao debate. É desse debate que Adorno escreve Dialética Negativa, obra que apresenta sua resolução sobre o primado do objeto, opondo-se à tradição filosófica alemã do idealismo, bem como com a nascente corrente fenomenológica de pesquisas no campo social, tal como elas se apresentavam como corrente filosófica à época. Nas suas pesquisas, Adorno trata da tese do primado do objeto em diversos momentos, como, por exemplo, em Dialética do Esclarecimento (Adorno \& Horkheimer, 2002), no texto introdutório intitulado Crítica Cultural e Sociedade, do livro Prismas (Adorno, 1997), e no texto Ensaio como Forma (Adorno, 1986), texto eminentemente teórico que não abandona os pressupostos defendidos por Adorno na Dialética Negativa. Todos esses escritos são produzidos no período de 1945-1950. A expressão primado do objeto aparece na obra de Adorno, no entanto, em um seminário na Universidade de Frankfurt, em 1962, intitulado Marx e os Conceitos Fundamentais da Sociologia (Maar, 2006). Essa tese seria propriamente descrita posteriormente em Dialética Negativa.

Para Adorno, enquanto "uma oposição brusca em relação ao ideal de ciência corrente, a objetividade de um conhecimento dialético precisa de mais, não de menos sujeito. Se não a experiência filosófica definha" (Adorno, 2009, p. 42).

O primado do objeto não é uma apologia à realidade tal como ela se apresenta ao sujeito e nem um a priori em que os elementos de uma realidade só fazem sentido ao sujeito pelo lugar que eles ocupam no conjunto das relações. Assim, do ponto de vista dos estudos organizacionais, a proposição de Adorno permite sustentar as críticas a dois modos dominantes de pesquisa nessa área. $\mathrm{O}$ modo positivista e empirista, marcado pelas relações fenomênicas causais, em que a realidade é apreendida pelo sujeito na forma como a mesma se apresenta a ele e na qual não cabe nenhuma interpretação além do imediatamente visível. O modo funcionalista e idealista, marcado pelo apriorismo abstrato, em que a compreensão da realidade depende do desvendamento das relações funcionais entre os fenômenos que a caracterizam. Embora se encontrem em lados opostos da construção epistêmica, esses dois modos absolutizam os conceitos e subjazem à falta do sujeito.

O problema do subjetivismo nas ciências, do ponto de vista de Adorno, segundo O'Connor (2004, p. 45), é que este -"assumes the priority of concepts or categories that are supplied by the subject for any given experience.... The thesis of the priority of the object holds that objects are irreducible to concepts, that they cannot be made identical with concepts". O objeto não pode ser reduzido ao conceito, pois, para Adorno, o conceito é a forma de representação do objeto e não o objeto ele mesmo. Assim, a crítica de O'Connor acerca da irredutibilidade do objeto ao conceito em nada inova a concepção de Espinosa segundo a qual o conceito do cão não late. Para melhor compreender o papel do subjetivismo e sua relação com a ciência idealizada em Adorno, faz-se necessário compreender o que este entende por conceito e o que são constelações. 


\section{Constelações e Conceitos}

Há uma tendência em algumas dimensões racionalistas da filosofia em colocar como princípio da sua unidade o conceito, quase estabelecendo um "domínio totalitário do conceito" (Adorno, 2009, p. 8). Essa proposição faz dos sistemas de compreensões filosóficas - que podem ser caracterizadas na totalidade da obra de um pensador, nas correntes filosóficas, nos paradigmas interpretativos, etc. - um processo de edificação voltado para a compreensão da realidade. Em princípio, esse não seria um problema, apenas uma escolha epistêmica. O problema é a forma como os conceitos são utilizados nessas edificações, responsáveis por estabelecer um sistema de compreensões.

Os conceitos são usados como elementos estruturais dos edifícios, quase sempre como materiais de resistência absoluta, capazes de sustentar os edifícios como se estes fossem inabaláveis. Esta atitude filosófica impede aceitar que os conceitos servem como momentos interpretativos da realidade e são feitos com os materiais da época em que eles são produzidos.

Neste contexto, a filosofia precisa se desencantar do conceito, pois só assim pode fugir da tendência autoafirmativa absoluta de achar que a realidade na sua totalidade pode ser compreendida pela consciência, em que os conceitos servem como elementos definitivos e capazes de oferecerem precisão e verdade absoluta. Com isso, "o desencantamento do conceito é o antídoto da filosofia. Ele impede o seu supercrescimento: ele impede que ela se autoabsolutize" (Adorno, 2009, p. 19).

Para Adorno, "a reflexão filosófica assegura-se do não conceitual no conceito" (2009, p. 18). É por meio daquilo que não pode ser apreendido na totalidade que o conceito também se estabelece. As ausências são tão importantes quanto os elementos que se apresentam ao filósofo para elaborar a edificação conceitual. Com essa perspectiva, o não conceitual faz parte do conceito, e é exatamente pelo não conceitual existir que a não identidade na relação sujeito $\leftrightarrow$ objeto se estabelece.

O sujeito pensa a realidade principalmente por concepções e por conceitos. Sem os conceitos, o sujeito pesquisador não tem como operar a ação de conhecer algo. No entanto, a história da filosofia indica que a primazia do sujeito tem sido responsável por absolutizar os conceitos, tendo em vista ser este o momento da realização do sujeito. Essa absolutização se dá pelo fato de o sujeito acreditar que está estabelecendo um domínio da natureza por meio da compreensão da realidade. Associado ao domínio de certos elementos conceituais nos círculos sociais, o conceito passa a ser reificado, quase uma mercadoria fetichizada, um fornecedor de identidades.

Para quebrar essa tendência do fetichismo do conceito, "o que se torna urgente é o que ele não alcança, o que é eliminado pelo seu mecanismo de abstração, o que deixa de ser um mero exemplar do conceito" (Adorno, 2009, p. 15). Isto requer uma postura dialética para compreensão da realidade. Mas não qualquer dialética. Somente a dialética capaz de abandonar os resquícios do idealismo e fazer da contradição dentro e fora do sujeito sua lógica permanente de movimento é capaz de evitar que os conceitos se absolutizem.

A tese idealista apresenta pressupostos que, na visão de Adorno, não promove um movimento dialético. A lógica é a da reificação, mediante o uso dos conceitos e da estrutura conceitual como forma de afastamento do sujeito do conhecimento do objeto. Essa reificação é fruto do pensamento da identidade, "havendo um domínio reificado da falsa objetividade no pensamento resultante da dialética entre dominação da natureza e domínio social" (Maar, 2006, p. 136).

A conceituação deve passar a decifrar a realidade, e não a defini-la, porque "os conceitos não existem apenas nas cabeças dos filósofos, mas estão na realidade efetiva das coisas elas próprias, de modo que quando falamos da essência designamos precisamente o que a sociedade, sem saber, já possui em si” (Adorno como citado em Maar, 2006, p. 143).

No campo dos estudos organizacionais, de fato, alguns conceitos são absolutizados, sendo incorporados ao saber pré-existente, pretendendo definir a realidade apesar dela. Nesse modelo de 
universalização conceitual encontram-se, por exemplo, os de burocracia, mérito, competência, autoridade, organização, entre outros, que definem a realidade como dada e não como o que deve ser decifrado. Para Adorno, não há possibilidade de um conceito universal existir, pois, se este se "dissolve ante o ente determinado, a filosofia não tem mais o direito de esperar pela totalidade" (Adorno, 2009, p. 120) Suas experiências de filósofo que se lançou na experiência de fazer experiência empírica nas ciências sociais, fizeram-no ver que a realidade é muito mais do que as explicações que as filosofias podem fornecer. A filosofia deve amparar-se na realidade e evitar criar um mundo próprio, hermeticamente fechado e logicamente coerente em sistemas de pensamentos absolutos. Essa postura fez das filosofias grandes edifícios racionalizados e compartilhados dentro de paradigmas particulares.

$\mathrm{Na}$ atualidade, por exemplo, “o argumento especializado degenera-se em técnica de especialistas desprovidos de conceitos em meio ao conceito, tal como se expande hoje academicamente na assim chamada filosofia analítica passível de ser aprendida e copiada por robôs" (Adorno, 2009, p. 33). A observação de Adorno demonstra o desencantamento com o que parte significativa da filosofia vem se tornando.

Questionamentos fundamentais precisam ser feitos para evitar cair em silogismos lógicos: é possível uma filosofia sem conceitos? Como é possível uma filosofia sem absolutização do conceito já que se pensa por conceitos? Adorno não propõe descartar o conceito na filosofia. Para ele, "a filosofia fundamental, implica necessariamente o primado do conceito" (Adorno, 2009, p. 120). A sua não absolutização pode ser evitada pelo primado do objeto, pela concepção que os objetos são materiais e que o sujeito é também objeto, embora diferenciado. Outro argumento importante é que todos os conceitos estão relacionados aos não conceitos para constituírem-se de forma inteligível. O conceito imediato é apenas um momento no processo de formação que está dentro de um vir-a-ser que jamais se realiza totalmente na consciência. A consciência não é capaz de compreender a totalidade, assim como a filosofia não é capaz de chegar ao saber absoluto por não ser a mera soma das consciências dos filósofos. "A reflexão filosófica assegura-se do não conceitual no conceito" (Adorno, 2009, p. 18).

O não conceitual, sendo indispensável para o conceito, elimina qualquer possibilidade de conceitos que estabeleçam os em si mesmos. A natureza identitária de algo não se realiza pelo aparente, mas também por aquilo que não está aparente, mas existe como algo ausente. Com isso, uma teoria do conhecimento absoluto não é possível, o que não implica necessariamente em uma forma de irracionalismo e de relativismo pós-moderno.

O não conceito é um ente que não se apresenta de forma imediata. Assim, "como o ente não é de modo imediato, mas apenas por meio e através do conceito, seria preciso começar pelo conceito e não pelo mero dado. O conceito do conceito mesmo tornou-se problemático" (Adorno, 2009, p. 134). O que se torna urgente para o conceito é o que ele não alcança. Por isso, a eliminação das propriedades do conceito por meio do mecanismo de abstrações do pensamento é algo tão importante quanto estabelecer inteligibilidade ao conceito. Iniciar pelo conceito não é o mesmo que propor uma préconceituação à realidade, mas buscar no conceito sobre uma dada realidade a interpretação originária para confrontá-la consigo mesma e com aquilo que não foi conceituado.

Daí que, para Adorno, o não conceito só pode ser conhecido por meio do conceito. A relação de mútua existência permite afirmar que existe uma totalidade em potência. Entretanto, essa totalidade como conhecimento não pode ser apreendida pelo pensamento, pois este só se realiza pelo princípio da não identidade. A totalidade em potência deve ser tratada como um vir-a-ser, sem a possibilidade de findar em um Saber Absoluto.

A unidade do saber, dessa forma, está no conceito, pois sem ele não é possível uma inteligibilidade. $\mathrm{O}$ conceito está entrelaçado em um todo não conceitual e manifesta-se quando apreendido pelo pensamento identificatório. Todavia, o princípio da não identidade denuncia que o conceito só pode se apresentar como conceito por um processo de reificação, pois, se assim não fosse, o seu momento de realização não existiria. Para não absolutizar o conceito como algo metafísico, é preciso entender que "o conceito é um momento como outro qualquer" (Adorno, 2009, p. 19) 
Mas é possível a existência do conceito puro, ou seja, um ente que em nada dependa de outros elementos externos a ele mesmo? Para Adorno, "o conceito puro, função do pensamento, também não pode ser radicalmente isolado do eu que é" (Adorno, 2009, p. 119). O princípio da não identidade é o elemento que possibilita que "todo e qualquer conceito, mesmo o conceito de ser, [reproduza] a diferença entre pensar e pensamento" (Adorno, 2009, p. 151). O pensamento é processo identificador, que se utiliza dos elementos lógicos para que o ente do conceito possa ser apreendido, mesmo que parcialmente e muitas vezes fragmentariamente. Em relação ao universal e o particular, "os atos identificadores que julgam se o conceito faz justiça àquilo que é apreendido e se o particular também preenche seu conceito, é o meio do pensamento da não identidade entre o particular e o conceito. E não apenas o meio do pensamento" (Adorno, 2009, p. 128).

Adorno adota como eixo a máxima de se confrontar o conceito pelo conceito. Para ele, apenas o conceito pode dizer o que o conceito é. Apenas na objetivação do conceito é possível desvelar o que o conceito encerra. Por isso, Adorno (2009) utiliza-se da palavra conceito para designar seu processo de dialética negativa. O conceito é, no sentido de que são os objetos que têm primazia. Porém, ele se constitui enquanto objeto, a partir dos significados atribuídos pelos sujeitos e pela sua historicidade (do próprio objeto). Por isso, Adorno utiliza-se das matrizes Expressão e Constelação de Ideias para buscar desvendar o conceito pelo conceito.

Segundo Adorno (2009, p. 142), "o conhecimento do objeto em sua constelação é o conhecimento do processo que ele acumula em si”. A noção de constelação de ideias é central para compreender o conceito. Na Dialética Negativa, Adorno apresenta a incorporação do procedimento constelatório. "As constelações são configurações que não descrevem, não conceituam, nem enquadram os fenômenos, mas constituem, por outro lado, sua interpretação objetiva" (Duarte, 2007, p. 24).

Em relação às ideias, por exemplo, elas relacionam-se às coisas como as constelações se relacionam às estrelas. Isso quer dizer que as ideias não são conceitos, nem suas leis. Também não servem para conhecer os fenômenos. Estes, por sua vez, não são critérios para a existência de ideias. Segundo Adorno (2009), as ideias são constelações eternas. "Na medida em que os conceitos se reúnem em torno da coisa a ser conhecida, eles determinam potencialmente seu interior, alcançam por meio do pensamento aquilo que o pensamento necessariamente extirpa de si” (Adorno, 2009, p. 141).

Os conceitos são fundamentais para conhecer o algo, a coisa. Mas os conceitos não são o algo ou a coisa. Eles apenas apontam as potencialidades deles. Os conceitos habitam os pensamentos e, numa constelação de ideias, são responsáveis por formar um sistema de interpretações. Todavia, a totalidade não pode ser conhecida pela força do pensamento, o que não tira a importância dos conceitos e da constelação de ideias como essenciais para se conhecer o algo, a coisa. As categorias seriam, dessa forma, partes aparentes das constelações que estão sujeitas às transformações por meio da Dialética Negativa. "Quando uma categoria se transforma - por meio da dialética negativa, a categoria da identidade e da totalidade -, a constelação de todas as categorias se altera, e, com isso, uma vez mais cada uma delas" (Adorno, 2009, p. 144).

Para Adorno, os conceitos não progridem por etapas até o conceito superior mais universal. Os conceitos fazem parte de uma constelação que ilumina o que há de específico no objeto e o seu entorno (Adorno, 2009, p. 140). A luz dos conceitos (se estes equivalessem às estrelas) é capaz de iluminar o objeto em análise, mas não de mostrar com total clareza o que ele realmente é. O que não está iluminado também está ali, mas não pode ser observado. Por isso, o objeto é sempre mais do que se pode observar dele. É o conceito e o não conceito. É a existência por aquilo que pode ser visto e aquilo que não pode ser visto, que está ausente do conceito. Esta concepção de Adorno indica que os conceitos não são verdades últimas que explicam um objeto, mas apenas uma ideia do que ele seja em si.

Os conceitos, na atualidade, tornaram-se um fim em si mesmo, um instrumento explicativo que tende à absolutização da compreensão. A fetichização do conceito é a manifestação da onipotência da 
consciência, que acredita que a realidade pode ser complemente conhecida por força do pensamento. Conceitos são momentos particulares do objeto e não a totalidade dele.

\section{Implicações para a Pesquisa em Administração: Considerações Finais}

A contribuição de Adorno para a epistemologia no âmbito das ciências sociais é relevante para que se possa avançar na área da pesquisa em estudos organizacionais em geral e na área da pesquisa em administração em particular. De fato, a pesquisa científica é instrumento por excelência para o desenvolvimento da teoria e para a ampliação do conhecimento. Entretanto, tem se tornado cada vez mais comum, em diversos programas de pós-graduação em administração, que a pesquisa seja padronizada, sendo considerado científico apenas o que se desenvolve segundo esse padrão.

A padronização decorre de uma concepção que considera as técnicas de pesquisa e os modelos de organização e apresentação dos trabalhos como metodologia. Esse fato é facilmente observado nos diversos livros sobre metodologia científica ou metodologia da pesquisa. Em geral, os livros seguem um mesmo roteiro, tratam dos mesmos assuntos de forma bastante semelhante, sugerem procedimentos parecidos e dão orientações iguais. O resultado é que teses e dissertações são produzidas em um mesmo formato, independentemente do objeto que se estuda, do tema e da abordagem. Algumas pesquisas podem se enquadrar nesse formato, mas imputar um padrão universal a todas as demais é forçar que procedimentos incompatíveis epistemologicamente, metodologicamente e teoricamente sejam reduzidos a uma e única representação. A metodologia não é uma sequência de técnicas, mas um conjunto de procedimentos, um processo, que se vale de técnicas diferenciadas.

Na perspectiva de Adorno (2009), esses procedimentos padronizados reduzem o lugar do sujeito na pesquisa e também a relação deste com o objeto. O sujeito assume o lugar da intermediação entre a teoria pronta e a realidade escolhida, ou seja, a pesquisa se restringe a teste de uma teoria, e a ela se submete. A ausência do sujeito e de sua relação com o objeto não produz formas de decifrar a realidade, mas formas de dispô-la segundo modelos abstratos de análise passíveis de serem generalizados de um objeto para outro. A reprodução destes modelos passa a caracterizar o que é pesquisa científica.

Entende-se que há uma relação entre epistemologia e metodologia.

A Epistemologia é a base de toda concepção referente ao relacionamento do sujeito pesquisador com a complexidade do conteúdo de seu objeto de estudo. A dificuldade de compreender a importância desta relação mesmo desemboca nos problemas que dizem respeito à orientação teórica e metodológica dos trabalhos (Faria, 2011, pp. 6-7).

A partir da proposta epistemológica de Adorno (2009), é possível indicar que uma pesquisa em administração deve considerar mais que técnicas e que referenciais teóricos pré-existentes.

As técnicas compõem o sistema metodológico, mas não se confundem com ele, pois o método é um procedimento vinculado à concepção e à produção do conhecimento e, portanto, à epistemologia. Os diferentes sistemas metodológicos podem se valer de mesmas técnicas, mas não as operam necessariamente da mesma forma. Assim, é preciso haver uma conciliação necessária entre as técnicas mais apropriadas de pesquisa, a Dimensão Epistemológica e a metodologia nela contida e que lhe corresponde (Faria, 2011, p. 9).

Dessa forma, como se procurou mostrar, a proposta de Adorno é, ao mesmo tempo, um método e uma epistemologia para a orientação de pesquisas que recusam a concepção positivista, funcionalista, pragmatista ou idealista. Sua aplicação à área da Administração é incipiente e tem se concentrado apenas em alguns poucos Estudos Organizacionais. Em síntese, a contribuição de Adorno para as pesquisas em administração, aqui exposta, materializa-se em pelo menos seis pontos. 
O primeiro refere-se ao combate à instituição dos sistemas totalitários de compreensão. Isso significa o questionamento daquelas pesquisas que se valem de uma teoria pronta e acabada, como se esta fosse um sistema de explicação total da realidade, para aplicá-la empiricamente em casos reais. Esta empreitada de Adorno, que tem como alvo a luta contra o sistema de compreensão totalitário, na área de administração não é incomum, ao contrário, trata-se de um modelo de larga utilização.

O segundo ponto indica que, quando os pensamentos são elementos da práxis, estes passam a ter potencial concreto no mundo objetivo. Isso significa que é a partir da práxis que se chega à teoria e não da teoria que se pode explicar a práxis que dela independe. Apenas no primeiro caso é possível agir na condição de transformar o mundo, organizá-lo, modificá-lo. No segundo caso, o que se consegue é se alienar ao mundo e aceitar que outros o modifiquem. Este ponto sugere a necessidade de uma relação concreta, entre o pesquisador e seu objeto de pesquisa, que supere a distância epistêmica entre ambos.

O terceiro ponto mostra que a primazia do objeto faz do sujeito um objeto qualitativamente distinto. Adorno (2009) mostra que o objeto só pode ser conhecido pela consciência e que as alterações qualitativas do objeto só são possíveis devido ao fato de o sujeito possuir uma consciência crítica quanto ao objeto coisificado. Portanto, um objeto não pode ser conhecido na sua totalidade, não porque o conhecimento da totalidade é uma impossibilidade inerente à condição humana (o que não deixa de ser correto), mas porque a consciência quanto ao objeto é um momento específico da realidade percebida, um momento de identidade que se realiza na realidade pela não identidade. Esse ponto reforça o anterior quanto à relação entre o sujeito pesquisador e o objeto de sua pesquisa.

O quarto ponto indica que o objeto a ser estudado não é nada sem o sujeito que vai estudá-lo, pois, sem o sujeito, o momento do objeto não existe. O pesquisador é desafiado a criar seus esquemas e sua capacidade de julgar, sob o risco de ser levado a interpretar o mundo tal como lhe é apresentado pelos esquemas prontos. Dessa forma, quando o pesquisador se apropria de um esquema de análise e o aplica a uma realidade, nada mais faz do que replicar o que já é conhecido na forma em que é conhecido. A realidade, assim, nada mostra além do que o pesquisador pretendia investigar. Esse ponto indica a fragilidade da pesquisa que se vale de teorias apriorísticas, sem críticas e elaborações, aplicadas diretamente à realidade para serem testadas.

$\mathrm{O}$ quinto ponto mostra que sujeito pensa a realidade principalmente por concepções e por conceitos. Sem os conceitos, o sujeito pesquisador não tem como operar a ação de conhecer algo. No entanto, isso não significa que o conceito antecede plenamente o exame da realidade, pois isso o absolutiza, levando o sujeito a acreditar que está estabelecendo um domínio do objeto por conta da compreensão conceitual da realidade. Como essa situação é constantemente reafirmada no mundo acadêmico, o conceito se transforma em um fetiche, um fornecedor de identidades que faz com que o pesquisador se reconheça como pertencente a tal ou qual modelo teórico. A conceituação deve passar a decifrar a realidade, e não a defini-la. Este ponto também coloca em causa uma questão fundamental: conceitos podem e devem ser criados sempre que a teoria existente não os tenha disponibilizado.

O sexto ponto, finalmente, mostra que, sendo a realidade estudada não plenamente cognoscível, aquilo que não se mostra somente pode ser conhecido por meio daquilo que se mostra, ou seja, o não conceito só pode ser conhecido por meio do conceito, pois a relação de mútua existência permite afirmar que existe uma totalidade em potência. Aqui surge a proposta de Adorno sobre as Constelações. Os conceitos fazem parte de uma constelação que ilumina o que há de específico no objeto e o seu entorno, que realça o objeto em análise, mas não mostra com total clareza o que ele realmente é. O que não está esclarecido também está ali, mas não pode ser observado. Isso leva Adorno a considerar que o objeto é sempre mais do que se pode observar dele. É o conceito e o não conceito. É a existência por aquilo que pode ser visto e aquilo que não pode ser visto, que está ausente do conceito. Essa concepção de Adorno indica que os conceitos não são verdades últimas que explicam um objeto, mas apenas uma ideia do que ele seja em si. Este ponto indica que a realidade não pode ser compreendida apenas pela leitura de sua aparência fenomênica. 
Esses seis pontos constituem, assim, a contribuição que se pode apropriar da proposição epistemológica de Adorno para os estudos organizacionais e para a pesquisa em administração. Tratase de uma proposição que tem o atributo de inovar pesquisas nesta área, gerar novos conceitos, formular novas teorias e sugerir novas práticas.

\title{
Notas
}

\begin{abstract}
${ }^{1}$ Juntamente com Horkheimer, Benjamin, Marcuse, Fromm, entre outros, Adorno fez parte do que é conhecido como a primeira geração do Instituto de Pesquisa Social de Frankfurt. A segunda geração foi representada por Habermas, seu exdiretor. A terceira geração é liderada pelo atual diretor do instituto, Axel Honneth. Da primeira até a terceira gerações, as proposições teóricas e epistemológicas sofreram importantíssimas mudanças. Da Teoria Crítica de inspiração marxista da primeira geração, chega-se, atualmente, a uma Teoria Crítica Hegeliana, idealista, fenomenológica, proposta por Honneth, A. (2007). Reificación: un studio en la teoria del reconocimiento. Buenos Aires: Katz; Honneth, A. (2009). Luta por reconhecimento: a gramática social dos conflitos sociais. São Paulo: Editora 34, muito bem criticada por Fraser, N. (2008a). Escalas de justicia. Barcelona: Herder; Fraser, N. (2008b). Adding insultto injury. London: Verso e que se encontra resumida em um debate entre ambos (Fraser, N., \& Honneth, A. (2003). Redistribution or recognition? A political-philosophical exchange. London: Verso).

${ }^{2}$ Adorno não estabelece uma prioridade hierárquica entre sujeito e objeto. A primazia do real não é um empirismo e sua perspectiva materialista não dogmática refere-se também ao fato de a ideia ser objeto. Trata-se, portanto, de mais sujeito no processo dialético, ou seja, não de uma simples apropriação do objeto pelo sujeito, mas de maior elaboração, pelo sujeito, do objeto.

${ }^{3} \mathrm{O}$ conceito de experiência, conforme utilizado por Adorno, difere da concepção empirista em si, quanto daquela incorporada no positivismo e no pragmatismo. Esta define a experiência como a identificação do particular com as categorias do real préestabelecidas. Para Adorno, experiência indica a possibilidade do outro, diverso à categoria identificatória. Experiência não remete à simples dedução (Maar, 2006).

${ }^{4}$ Adorno era avesso, por princípio, a uma delimitação disciplinar da filosofia e da sociologia (Adorno, 1973, 1993a, 2009).

${ }^{5}$ Adorno refere-se a esta motivação pessoal em diversos escritos e cartas aos colegas Thomas Man, Umberto Eco, etc. Muitos de seus biógrafos revelam que Adorno sofreu bastante por ter ficado isolado nos EUA, sem notícias claras sobre o que estava acontecendo na Alemanha e Europa. Quando terminou a Segunda Guerra e vários dados foram divulgados para o mundo, Adorno tornou-se ciente das atrocidades dos campos de concentração. Ele revela em cartas a colegas que voltaria para Alemanha e se comprometeria a compreender como um país tão desenvolvido, berço dos grandes pensadores do mundo, pátria dos filósofos idealistas e críticos, permitiu que Auschwitz acontecesse.
\end{abstract}

\section{Referências}

Adorno, T. W. (1973). Erziehungnach Auschwitz (GesammelteSchriften). Frankfurt, Germany: Suhrkamp.

Adorno, T. W. (1986). O ensaio como forma. In G. C. (Org.), Sociologia: Adorno. São Paulo: Ática.

Adorno, T. W. (1991). Actualidad de la filosofía (Colección Pensamiento Contemporáneo). España, Barcelona: Ediciones Piados.

Adorno, T. W. (1993b). Hegel: three studies. Cambridge, MA: MIT Press.

Adorno, T. W. (1993a). Mínima moralia. Rio de Janeiro: Ática.

Adorno, T. W. (1995). Palavras e sinais: modelos críticos 2. Petrópolis, RJ: Vozes.

Adorno, T. W. (1997). Prisms. Massachussets: The MIT Press.

Adorno, T. W. (2001a). Epistemología e ciencias sociales. Madri: Ediciones Cátedra.

Adorno, T. W. (2001c). Kant's critique of pure reason. California: Stanford University Press. 
Adorno, T. W. (2001b). Metaphysics: concept and problems. California: Stanford University Press.

Adorno, T. W. (2002a). Aesthetic theory. London and New York: Continnum.

Adorno, T. W. (2002b). The stars down to earth and other essays on the irrational in cultura. London and New York: Routledge.

Adorno, T. W. (2009). Dialética negativa. Rio de Janeiro: Jorge Zahar.

Adorno, T. W., \& Eisler, H. (1976). El cine y la musica. Madrid: Editorial Fundamentos.

Adorno, T. W., \& Horkheimer, M. (2002). Dialectic of enlightenment. California: Stanford University Press.

Althusser, L. (1967). Análise crítica da teoria Marxista. Rio de Janeiro: Zahar Editores.

Althusser, L., \& Badiou, A. (1979). Materialismo histórico e materialismo dialético. São Paulo: Global Editora.

Batista-dos-Santos, A. C., Alloufa, J. M. L., \& Nepomuceno, L. H. (2010). Epistemologia a metodologia para as pesquisas críticas em administração: leituras aproximadas de Horkheimer e Adorno. Revista de Administração de Empresas, 50(3), 312-324. doi: 10.1590/S003475902010000300007

Buck-Morss, S. (1977). The origins of negative dialectics. Brighton: Harvester Press.

Chiarello, M. (2007). Em defesa de Adorno: a propósito das críticas endereçadas por Giorgio Agamben à dialética Adorniana. Kriterion, 48(115), 183-201. doi: 10.1590/S0100512X2007000100011

Claussen, D. (2008). Theodor W. Adorno: one last genius (R. Livingstone, Trans.). Massachusetts, London: Belknap Press of Harvard University Press. (Original work published 2003)

Duarte, R. (2007). Reflexões sobre dialética negativa, estética e educação. In B. Pucci, P. Goergen, \& R. Franco (Orgs.), Dialética negativa, estética e educação (pp. 76-92). Campinas: Alínea.

Faria, J. H. (2004). Economia política do poder (Vol. 3). Curitiba: Juruá.

Faria, J. H. (2011). Epistemologia em estudos interdisciplinares [Working Paper $\mathrm{n}^{\circ} 1$ ]. Economia Política do Poder e Estudos Organizacionais, Curitiba, PR, Brasil.

Faria, J. H., \& Meneghetti, F. K. (2011). Dialética negativa e a tradição epistemológica nos estudos organizacionais. Organização \& Sociedade, 18(56), 119-137.

Habermas, J. (1990). Discurso filosófico da modernidade. Lisboa: Dom Quixote.

Hegel, G. F. (2008). Fenomenologia do espírito. Petrópolis: Vozes.

Horkheimer, M., \& Adorno, T. W. (1978). Sociologia e investigação social empírica. In M. Horkheimer \& T. W. Adorno (Orgs.), Temas básicos de sociologia (pp. 120-131). São Paulo: Cultrix.

Jameson, F. (1997). O marxismo tardio: Adorno, ou a persistência da dialética. São Paulo: Editora da UNESP e Editora Boitempo.

Jay, M. (1984). Adorno. Londres: Fontana.

Kant, I. (2008b). Crítica da razão prática. São Paulo: Martin Claret. 
Kant, I. (2008a). Crítica da razão pura (2a ed.). São Paulo: Martin Claret.

Lukács, G. (1959). El asalto a la razón: la trayectoria del irracionalismo desde Schelling hasta Hitler. Mexico, D. F: Fondo de Cultura Economica.

Maar, W. L. (2006). Materialismo e primado do objeto em Adorno. Trans/Form/Ação, 29(2), 133-154. doi: $10.1590 / \mathrm{S} 0101-31732006000200011$

Maranhão, C. M. S. A. (2010). Indústria cultural e semiformação. Análise curricular da formação dos administradores (Tese de doutorado). Universidade Federal de Minas Gerais, Belo Horizonte, MG, Brasil.

Maranhão, C. M. S. A., \& Vilela, J. R. P. X. (2010, setembro). Teoria crítica e pesquisa empírica: um estudo sobre Theodor Adorno. Anais do Encontro Nacional da Associação Nacional de PósGraduação e Pesquisa em Administração, Rio de Janeiro, RJ, Brasil, 34.

Marx, K. (2010). Manuscritos econômicos filosóficos. São Paulo: Boitempo.

Marx, K. (2011). O 18 brumário de Luís Bonaparte. São Paulo: Boitempo.

Marx, K. (2013). O capital (Livro I). São Paulo: Boitempo.

Musse, R. (2003). Passagem ao materialismo. Lua Nova,(60), 97-116. doi: 10.1590/S010264452003000300006

Musse, R. (2007). Elementos da crítica de Adorno a Kant. Dois Pontos, 4(1), 201-216.

Nobre, M. S. (1998). A dialética negativa de Theodor W. Adorno: a ontologia do estado falso. São Paulo: Iluminarus/FAPESP.

O'Connor, B. (2004). Adorno's negative dialectic: philosophy and the possibility of critical rationality. Cambridge, MA: MIT Press.

Paes de Paula, A. P. (2008). Teoria crítica nas organizações. São Paulo: Thomson Learning.

Paes de Paula, A. P. (2012). Estilhaços do real: o ensino de administração em uma perspectiva benjaminiana. Curitiba, PR: Juruá Editora.

Pucci, B., Goergen, P., \& Franco, R. (Orgs). (2007). Dialética negativa, estética e educação. Campinas: Alínea.

Rose, G. (1978). The melancholy science. An introduction to the thought of Theodor W. Adorno. London: Macmillan.

Rüdiguer, F. (2004). Theodor Adorno e a crítica à indústria cultural: comunicação e teoria crítica da sociedade. Porto Alegre: EDIPUCRS.

Thomson, A. (2010). Para compreender Adorno. Petrópolis, RJ: Vozes.

Wiggershauss, R. (1994). The Frankfurt school: its history, theories and political significance. Cambridge: Polity.

Wilson, R. (2007). Theodor Adorno. New York: Routledge.

Vásquez, A. S. (1977). Filosofia da práxis (4a ed.). Rio de Janeiro: Paz e Terra. 